\title{
ĐỨT CộT CƠ SAU SỬA VAN HAI LÁ DÙNG DÂY CHẦNG NHÂN TẠO
}

\author{
Nguyễn Hoàng Hà*, Đặng Quang Huy*, Đoàn Quốc Hung***
}

\section{TÓM TẮT:}

Kỹ thuật sửa van hai lá dùng dây chằng nhân tạo vật liệu Gore Tex là một kỹ thuật phổ biến trên thế giới trong sửa van hai lá. Dây chằng nhân tạo với chất liệu Gore Tex (còn được gọi là Neo Chordae) được sử dụng lần đầu để thay thế dây chằng van hai lá bởi Fratter[1][10]. Tirone David đã phát triển và làm cho kỹ thuật này trở nên phổ biến nhất trong các kỹ thuật sửa van hai lá khi là van bị sa do đứt, thiếu hoạc dài dây chằng [5]. Ở Việt nam việc sử dụng dây chằng nhân tạo trong sửa van hai lá mới được áp dụng. Tại Bệnh viện tim Hà nội chúng tôi sử dụng kỹ thuật này cho tất cả các trường hợp sa van lá trước và một số trường hợp sa van lá sau. Chúng tôi xin báo cáo một trường hợp ca lâm sàng có biến chứng hiếm gặp là đứt cột cơ tại chỗ cố định dây chằng nhân tạo sau khi phẫu thuật sửa van hai lá ít xâm lấn.

\section{BÁO CÁO CA LÂM SÀNG :}

Bênh nhân nam 59 tuổi có tiền sử lao phổi điều trị ổn định cách 20 năm, trước khi vào viện 10 ngày bệnh nhân xuất hiện khó thở nhiều, mệt mỏi.Khi vào viện bệnh nhân trong tình trạng NYHA II, trên siêu âm thành ngực và siêu âm thực quản đều kết luận hở van hai lá nhiều do sa lá sau vùng $P 2$ và $P 3$, một bản siêu âm thành ngực kết luận sa toàn bộ lá sau, chức năng tâm thu thất trái tốt, chỉ số EF $60 \%$ DD $58 \mathrm{~mm}$, áp lực động mạch phổi tâm thu $70 \mathrm{~mm} \mathrm{Hg}$, kích thước nhĩ trái $35 \mathrm{~mm}$. Bệnh nhân được chụp mạch vành cho kết quả hẹp nhẹ hệ mạch vành, điện tâm đồ nhịp xoang 70 chu kỳ/phút. Sau khi được điều trị nội khoa ổn định bệnh nhân được phẫu thuật theo chương trình với chẩn đoán trước mổ: Hở van hai lá nhiều do thoái hóa, dự kiến sửa van hai lá có vòng van. Diễn biến cuộc mổ: Tuần hoàn ngoài cơ thể được thiết lập qua động mạch và tĩnh mạch đùi phải, đường mở ngực $6 \mathrm{~cm}$ trước bên phải có hỗ trợ nội soi. Bệnh nhân được cặp động mạch chủ và bảo vệ cơ tim bằng dung dịch custodiol xuôi dòng qua kim gốc động mạch chủ. Van hai lá được bộc lộ qua rãnh Waterson bằng bộ vén nhĩ trái nội soi. Kiểm tra thương tổn thoái hóa lá sau dày và sa vùng $\mathrm{P} 2, \mathrm{P} 3$, đứt dây chằng lá sau vùng $\mathrm{P} 2$ và một phần vùng $\mathrm{P} 3$, kèm theo có giãn vòng van theo chiều trước sau. Phẫu thuật viên quyết định sử dụng Loop technique với ba vòng chỉ Gore Tex CV5. 3 vòng chỉ được cố định vào cột cơ sau trong bằng cách xuyên kim qua vùng chỏm xơ của cột cơ có miếng độn (pledgets) sau đó buộc 12 nơ chỉ. Phía bờ tự do lá sau các vòng chỉ được cố định bằng các mũi chỉ Gore Tex rời. Bệnh nhân được đặt vòng van hai lá kín loại nửa cứng số 32 của hãng Sorin. Kiểm tra bằng bơm nước van hai lá kín nhưng diện áp không đều. Sau khi đóng các buồng tim, đuổi khí, thả cặp động mạch chủ tim đập lại tốt. Siêu âm thực quản tại phòng mổ van hai lá kín. Diễn biến hậu phẫu ổn định. Bệnh nhân được xuất viện sau trong tình trạng sức khỏe tốt. Siêu âm sau mổ van hai lá hở nhẹ, chức năng tâm thu thất trái tốt. Sau khi xuất viện 10 ngày bệnh nhân đột nhiên thấy xuất hiện khó thở phải tái nhập viện trong tình trạng phù hai chân, tràn dịch màng phổi. Siêu âm phát hiện hở van hai lá nhiều với hai dòng hở, dòng hở

\footnotetext{
* $B V$ Tim Hà Nội

** BV HN Việt Đức, Trưòng ĐH Y Hà Nội

Người chịu trách nhiệm khoa họ: PGS.TS.Đoàn Quốc Hung

Ngày nhận bài: 01/05/2019 - Ngày Cho Phép Đăng: 15/05/2019

Phản Biện Khoa học: PGS.TS. Đặng Ngọc Hùng GS.TS. Lê Ngoc Thành
} 
trung tâm nhẹ và một dòng hở lớn hướng về vách liên nhĩ, thất trái và nhĩ trái không giãn, chức năng tâm thu thất trái còn bù, $\mathrm{EF} 58 \%$, áp lực động mạch phổi $60 \mathrm{mmHg}$, trên siêu âm thành ngực không đánh giá được tình trạng của dây chằng nhân tạo. Bệnh nhân cũng chụp mạch vành kiểm tra không thấy thương tổn . Bệnh nhân được mổ lại bán cấp cứu với chẩn đoán: Hở van hai lá cấp sau mổ sửa van theo dõi tổn thương dây chằng nhân tạo. Bệnh nhân được mở ngực đường dọc giữa xương ức, thiết lập tuần hoàn ngoài cơ thể động mạch chủ, 2 tĩnh mạch chủ, bảo vệ cơ tim xuôi dòng bằng dung dịch liệt tim máu ấm. Vào nhĩ trái qua vách liên nhĩ kiểm tra thương tổn: Ba vòng dây chằng nhân tạo vẫn còn gắn trên lá sau van hai lá, phía cột cơ bị bật ra khỏi chỗ khâu cố định với một phần cột cơ vẫn gắn vào miếng độn và dây chằng nhân tạo. Kết luận trong mổ là hở hai lá do đứt cột cơ tại chỗ cố định các vòng dây chằng nhân tạo. Sau khi đánh giá lại tình trạng tại chỗ của van hai lá Phẫu thuật viên quyết định không tiếp tục sửa van, thay van hai lá cơ học On-X số 27/29mm giữ lại một phần lá sau van hai lá. Sau mổ bệnh nhân ổn định xuất viện sau 3 tuần điều trị.

\section{BÀN LUẬN:}

Thoái hóa van hai lá là nguyên nhân thường gặp gây hở van trên lâm sàng. Thoái hóa van gây thương tổn trên mô van và dây chằng với biểu hiện là sa lá van. Có nhiều kỹ thuật sửa van được áp dụng trong trường hợp sa van nhưng Sử dụng dây chằng nhân tạo là một kỹ thuật thường quy, phổ biến, hiệu quả và ít biến chứng. Do ở Việt nam chúng ta nguồn dây chằng nhân tạo còn hiếm nên hầu hết dây chằng nhân tạo được sử dụng cho sa lá trước van hai lá. Các trường hợp sa lá sau kỹ thuật hay được áp dụng là cắt tam giác, tứ giác kết hợp với khâu thu nhỏ vòng van[4]. Tuy nhiên cũng có những nghiên cứu gợi ý kỹ thuật không cắt lá sau có vẻ giúp đặt được vòng van lớn hơn và bảo tổn được vận động của vòng van[8]. Khi sử dụng dây chằng nhân tạo khó khăn lớn nhất là xác định chiều dài chính xác của dây chằng nhân tạo, kỹ thuật cố định dây chằng nhân tạo trên cột cơ và tổ chức lá van[9]. Các biến chứng của dây chằng nhân tạo hiếm gặp và phần lớn liên quan đến đứt dây chằng nhân tạo trong giai đoạn sớm hoặc giai đoạn muộn với các nguyên nhân được nhắc đến là: Vôi hóa dây chằng làm thay đổi tính đàn hồi của vật liệu Gore Tex và làm đứt dây chằng nhân tạo[2][3][5][6]. Một nguyên nhân cũng được nhắc đến là viêm hoạc thương tổn cơ học trong khi thao tác trên dây chằng (do dụng cụ cầm nắm, hoạc do cặp clip)[7]. Biến chứng đứt chỗ bám của dây chằng nhân tạo vào cột cơ hầu như không được các tác giả nhắc đến. Tác giả duy nhất mà chúng tôi tìm thấy là Tironde David có gặp một trường hợp trong số 606 bệnh nhân sử dụng dây chằng nhân tạo với thời gian theo dõi trung bình là 10 năm[5]. Có nhiều kỹ thuật cố định dây chằng nhân tạo vào cột cơ như khâu mũi chữ $\mathrm{X}$ hoặc mũi chữ $\mathrm{U}$ có miếng độn pledget nhưng tất cả đều khuyến cáo là cần khâu vào phần xơ đầu cột cơ [5][9]. Kỹ thuật của chúng tôi tiến hành là kỹ thuật loop tức là dùng chỉ Gore Tex CV 5 khâu qua lại nhiều lần qua miếng độn Pledget tạo ra nhiều vòng chỉ sau đó sẽ khâu hai mũi kim qua chỏm cột cơ và buộc từ 12 đến 15 nơ chỉ để cố định các vòng chỉ. Tiếp tục chúng tôi sẽ dùng chỉ Gore Tex khâu cố định từng vòng chỉ lên bờ tự do của van hai lá tạo nên dây chằng van hai lá nhân tạo. Khi thực hiện kỹ thuật này thì toàn bộ lực của các dây chằng nhân tạo sẽ tác động lên một điểm bám ở cột cơ tuy nhiên cũng chưa có tác giả nào ghi nhận bị đứt cột cơ khi thực hiện kỹ thuật loop. Khi phân tích hồi cứu chúng tôi không chắc chắn được nguyên nhân trực tiếp gây đứt chỗ bám cột cơ nhưng có thể 
nghĩ đến một vài nguyên nhân có thể trực tiếp hoặc phối hợp gây nên biến chứng này.

- Trên bệnh nhân này diện sa lá sau van hai lá rất lớn chiếm hơn $50 \%$ diện tích lá sau chính vì vậy phẫu thuật viên không muốn dùng kỹ thuật cắt tứ giác và khâu hẹp vòng van vì có thể làm co kéo quá nhiều các mô xung quanh hay hở van thứ phát. Việc sử dụng dây chằng nhân tạo có vẻ hợp lý hơn nhưng cũng do diện sa lớn dẫn đến lực tác động lên chỗ bám của cột cơ nhiều có thể dẫn đến làm đứt chỗ bám của dây chằng nhân tạo vào cột cơ

- Diện sa van hai lá của bệnh nhân ở phần $\mathrm{P} 2, \mathrm{P} 3$ với một phần diện sa nằm vượt quá đường giữa lá sau. Vì muốn đơn giản kỹ thuật và sử dụng một sợi chỉ Gore tex nên chúng tôi làm một hệ thống vòng chỉ và cố định vào cột cơ sau trong. Về mặt nguyên tắc giải phẫu phân bố các dây chằng van tim, các dây chằng xuất phát từ mỗi cột cơ sẽ không vượt qua đường giữa. Trên bệnh nhân này dây chằng nhân tạo của chúng tôi có một phần vượt qua đường giữa, có thể dẫn đến làm thay đổi lực tác động lên các dây chằng, xoắn nhẹ có thể dẫn đến thiếu máu và đứt cột cơ.

- Khi kiểm tra bằng bơm nước mặc dù van hai lá kín nhưng đường áp của các lá van không đều có thể do lực kéo không đều trên các dây chằng nhân tạo dẫn đến có thể tăng lực kéo lên một vị trí hoặc một hướng của một vòng chỉ dẫn đến đứt cột cơ.

- Bệnh nhân được phẫu thuật ít xâm lấn vì vậy cần phải buộc chỉ Gore tex bằng dụng cụ đẩy chỉ "Knot Pusher". Rất nhiều các phẫu thuật viên dùng dụng cụ này để cố định chỉ Gore tex nhưng cũng chưa có trường hợp nào được ghi nhận dây tổn thương cột cơ. Chúng tôi chỉ giả định đây có thể là một yếu tố góp phần làm tăng nguy cơ thương tổn cột cơ.

Với diễn biến thực tế của bệnh nhân thời điểm đứt chỗ bám dây chằng vào cột cơ khoảng 3 tuần sau mổ khó có thể nguyên nhân thương tổn do tác động cơ học trong khi mổ, cũng khó là các nguyên nhân gây thiếu máu gây đứt cột cơ. Nguyên nhân nhiều khả năng nhất là diện sử dụng dây chằng nhân tạo quá rộng dẫn đến lực co kéo lên cột cơ lớn, kết hợp với thương tổn sa van vượt quá đường giữa làm lực co kéo không đều có thể gây xoắn dẫn đến đứt cột cơ gây hở van tái phát.

\section{KẾT LUẬN}

Loop technique là một kỹ thuật phổ biến, hiệu quả và dễ áp dụng trong sửa van hai lá do sa van tuy nhiên khi thực hiện cần tuân thủ những nguyên tắc sửa van hai lá kinh điển của Carpentier cũng như các nguyên tắc về phân bố dây chằng nhân tạo. Trong những trường hợp phải sửa van hai lá có các thương tổn tương đối phức tạp cần cẩn thận đánh giá kỹ khi chọn đường mổ ít xâm lấn nhất là với các phẫu thuật viên mới làm quen với đường mổ này.

\section{TÀI LIỆ THAM KHẢO}

1. Frater RWM, Gabbay S, Shore D, Factor S, Strom J. Reproducible replacement of elongated or ruptured chordae mitral valve chordae. Ann Thorac Surg. 1983; 35:14-28.

2. Bortolotti U, Celiento M, Pratali S, Anastasio G, Pucci A. Recurrent mitral regurgitation due to ruptured artificial chordae: case report and review of the literature. J Heart Valve Dis. 2012 Jul;21(4):440-3.

3. Butany, J., Collins, M.J., David, T.E. Ruptured synthetic expanded polytetrafluoroethylene chordae tendinae. Cardiovasc Pathol. 2004;13:182-184

4. Carpentier, A. Cardiac valve surgerythe "French correction". J Thorac Cardiovasc Surg. 1983; 86: 323-337 
5. David, T.E., Armstrong, S., Ivanov, J. Chordal replacement with polytetrafluoroethylene sutures for mitral valve repair: a 25-year experience. $J$ Thorac Cardiovasc Surg. 2013;145:1563-1569

6. Dumont, E., Gillinov, A.M., Blackstone, E.H., Sabik, J.F. III, Svensson, L.G., Mihaljevic, T. et al.Reoperation after mitral valve repair for degenerative disease. Ann Thorac Surg. 2007; 84: 444-450

7. Kudo, M., Yozu, R., Okamoto, K. Recurrent mitral regurgitation due to ruptured ePTFE neochordae after mitral valve repair by the loop technique: a report of case. Ann Thorac Cardiovasc Surg. 2014;:746-749
8. Patrick Perier.Toward a New Paradigm for the Reconstruction of Posterior Leaflet Prolapse: Midterm Results of the "Respect Rather Than Resect" Approach. Ann Thorac Surg 2008;86:718-25

9. Von Oppell, U.O. and Mohr, F.W. Chordal replacement for both minimally invasive and conventional mitral valve surgery using premeasured Gore-Tex loops. Ann Thorac Surg. 2000; 70: 2166-2168

Zussa, C., Frater, R.W., Polesel, E., Galloni, M., and Valfré, C. Artificial mitral valve chordae: experimental and clinical experience. Ann Thorac Surg. 1990; 50: 367-373. 